
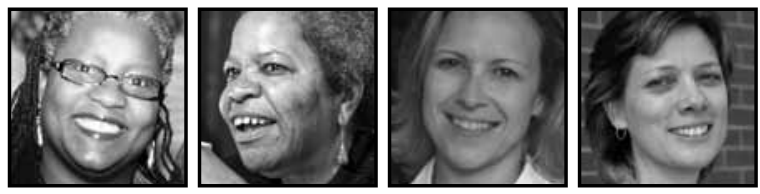

\title{
The Journey From Trepidation to Theory: P-12 Teacher Researchers and Creativity
}

\author{
Jenice L. View, George Mason University \\ Mary Stone Hanley, Hanley Arts \& Associates \\ Stacia Stribling, George Mason University \\ Elizabeth DeMulder, George Mason University
}

\section{ABSTRACT}

There is typically no expectation of creativity in the context of teacher professional development programs. Yet, the Common Core Curriculum and other constructs demand that teachers exhibit considerable creativity in curriculum and instruction. The challenge then for teacher educators is to support each learner's individual growth toward greater cognitive complexity. This research examined the experience of a group of P-12 classroom teachers who explored the use of the arts to nurture their own creative processes, classroom research, understanding of difference, particularly race and culture, and instructional practices in the context of a graduate teacher professional development program.

Art hurts. Art urges voyages--and it is easier to stay at home.

(Brooks, 1967, p. 1)

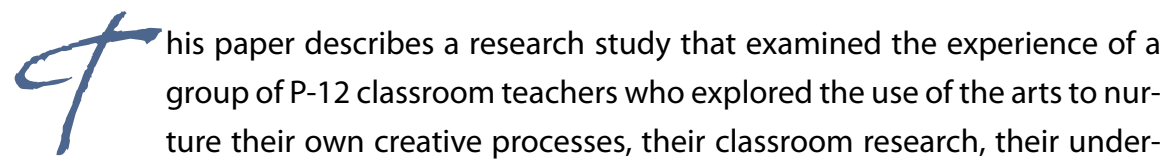
standing of difference, particularly race and culture, and their instructional practices in the context of a graduate teacher professional development program. Four faculty colleagues in the same graduate program conducted the research in two parts. Two interviewed people of diverse races about their schooling experiences; wrote poetry 
using the data; and created a video of a reading of the poetry. Two colleagues subsequently showed the video to their graduate students who are in-service teachers. The students discussed the form and content and wrote poetry after they had interviewed parents and teachers from cultural backgrounds other than their own. This article primarily describes the process after the video was produced.

\section{Theoretical Frameworks}

Six important frameworks helped us to situate and understand our work: creativity theories (e.g., Beghetto \& Kaufman, 2007; Doyle, 2011; Egan, 1992; Runco, 1966); counternarrative as described in critical race theory (e.g., Decuir \& Dixson, 2004; Delgado \& Stefancic, 2001; Ladson-Billings \& Tate, 1995; Lynn et al., 2002); artsbased educational research (e.g., Barone, 2008; Barone \& Eisner, 1997; Cahnmann, 2003; Eisner, 1980, 1995, 2008; Leggo, 2008); dialogical instruction and learning (e.g., Shor, 1992, Wink, 2005); Bloom's Taxonomy (Anderson \& Krathwhol in Krathwohl, 2002; Bümen, 2007); and constructive-developmental adult development theory (e.g., Kegan, 1982; Mezirow, 1990, 1991).

\section{Creativity Theories}

Egan (1992) contends that imagination calls for flexibility in thought and an integration of emotionality, rationality, and meaning. Egan describes meaningmaking as a dynamic process which uses multiple components stating,

[facts] mix in with the complex of shifting emotions, memories, intentions, and so on that constitute our mental lives...All kinds of associations curl around each new fact, there is endless blending and coalescing, and this activity involves the imagination. The more energetic and lively the imagination, the more are facts constantly finding themselves in new combinations and taking on new emotional colouring as we use them to think of possibilities, of possible worlds. (p. 50)

Doyle (2011) describes a creative episode as having an initial problem, progressing through a process that ends in success, which can then be judged by others. Runco (1966) defines creativity as manifested in the intentions and motivation to "transform the objective world into original interpretations, coupled with the ability to decide when this is useful and when it is not" (p. 4). Creativity need not be judged 
by others; judgment is based on personal criteria. Beghetto and Kaufman (2007) build on Runco's work by theorizing a continuum of creativity that begins with mini-c, that may advance to little-c (everyday creativity) and big-C (eminent or field changing) processes of creativity. They define mini-c creativity as:

...the novel and personally meaningful interpretation of experiences, actions, and events [which] need not be original or (even meaningful) to others. Indeed, the judgment of novelty and meaningfulness that constitutes mini-c creativity is an intrapersonal judgment. (p. 73)

The authors further state that mini-c creativity is central to meaning-making: Little-c creativity is the sort inherent in everyday activities, that manifests on a smaller scale than big-C creativity, and Beghetto and Kaufman give the difference between Charlie Parker (big-C), who changed jazz with his innovations and a local jazz band (little-c) that creates music, but has not significantly changed the field of music; nevertheless, little-c and big-C creativity are formed initially by the important intrapersonal work in mini-c creativity.

\section{Bloom's Taxonomy}

Created in 1956 by Benjamin Bloom, the Taxonomy of Educational Objectives has long been a popular tool for designing and classifying educational goals, objectives, and standards. The original Taxonomy consisted of six categories and subcategories, organized in a hierarchical framework of ability and skill development (Krathwohl, 2002).

A 2000 revision changed Bloom's nouns (knowledge, comprehension, application, analysis, synthesis, evaluation) to verbs (remembering, understanding, applying, analyzing, evaluating, creating) to state more clearly the process for achieving more advanced learning outcomes (Revised Bloom's Taxonomy, n.d.). Most important to this study, however, is the assignment of "creating" - or the process of putting elements together to form a coherent or functional whole; reorganizing elements into a new pattern or structure through generating, planning, or producing-as the highest order outcome in learning.

\section{Counter-Narrative}

Educational theorists engaged in critical race theory (Decuir \& Dixson, 2004; Ladson-Billings \& Tate, 1995; Lynn et al., 2002) propose the use of counter-narrative 
to reveal the lived experience of race in education. In so doing, educators may gain a view of being and meaning that the experience of race provokes. Delgado and Stefancic (2001) assert that counter-narrative "aims to cast doubt on the validity of accepted premises or myths, especially ones held by the majority" (p. 144). Hence, counter-narratives in the educational context may be a means to portray the multiple layers and intersections of race (and other forms of difference) in the culture of education.

For the purposes of this study, researchers were interested both in the ways of using counter-narrative to uplift the stories of people previously unknown to the listener, and in the possibilities of creating counter-narratives through a process of arts-based educational research.

\section{Arts-Based Educational Research (ABER)}

Arts-based educational research, the use of the elements and practices of the arts to inform our understanding of education, is a perfect complementary framework to produce CRT counter-narratives: Through ABER researchers might touch subjectivities. Eisner (2008) asserts that ABER works to "apply the arts in some productive way to help us understand more imaginatively and more emotionally problems and practices that warrant attention in our schools" (p. 18). Barone and Eisner (1997) describe attributes of ABER that connect directly to counter-narratives by constructing a virtual space that "possesses a capacity to pull the person who experiences it into an alternative reality," which is the goal of critical race theorists and arts-based researchers alike (p. 73). In addition, historically the arts have often represented social justice. Barone (2008) asserts that ABER can be used to contest worldviews and "influence the public consciousness by critiquing the politically conventional and the socially orthodox" (p. 36). Thus, ABER may provoke percipients to imagine an experience of race in education outside of their own frame of reference, or to some degree unsettle emotional and cognitive barriers that limit their ability to empathize.

A subset of ABER theory is poetic inquiry. Cahnmann (2003) posits that the use of poetry in qualitative research provides opportunities to express meaning in innovative and insightful ways that are not accessible in other forms. Poets use metaphor, rhythm, alliteration, and other means to represent ideas and emotions that are multi-layered. In effect, a poetic representation provides a thick description (Geertz, 1973) of the poet/researcher's interpretation of events. 


\section{Dialogical Instruction and Learning and Constructive-Developmental Adult Development Theory}

Dialogical instruction and learning is an ancient form of schooling in which all people are free to ask questions, offer claims, and to share power in an argument (such as Socratic dialogues). The goal of dialogic instruction and learning is social transformation. From among more recent theorists and practitioners (e.g., Vygotsky, Bakhtin, and Freire as referenced in Renshaw, 2004), the authors drew on the work of Joan Wink (2005), a White expert classroom teacher using dialogical instruction and learning with diverse student populations whose lived experience is similar to the setting of this research.

Constructive-developmental theorists (e.g., Kegan, 1982; Mezirow, 1991) suggest that transformative learning and development occur for individuals in contexts that support meaning-making through critical reflection. Embedded in these theories is the assumption that development moves hierarchically from simple to more complex and elastic cognitions as a result of this meaning-making. Through critical reflection that includes perspective taking and dialogue with others, individuals often arrive at "a more inclusive, differentiated, permeable and integrated perspective" (Mezirow, 1990, p. 14).

As four faculty colleagues, we wondered how an iterative process of artsbased educational research could help P-12 classroom teachers develop understanding of "difference" in order to offer more effective classroom instruction to diverse student populations. Two of us, Hanley and View (2010), used poetry to describe our research on race in education; Stribling and DeMulder then considered "difference" by incorporating Hanley and View's poetic counter-narratives of critical race theory and through dialogic instruction and learning explored how the experience of poetrywriting-as-data-analysis might affect graduate students in their roles as artists and researchers.

We focused on the goals of transformative adult education (Mezirow, 1990) and how teachers can improve their creativity as a part of their own growth as teachers in the service of their students' development. Our thesis was that to change teacher practice, teachers must experience what a creative practice looks like; therefore by engaging teachers in an explicitly creative process, they might develop awareness of how to change their practice in ways that would offer enriched learning opportunities through creative exploration in their own classrooms. Teacher educators need to consider the kinds of curricular experiences that effectively support teachers to engage in this work. 


\section{Methods}

The site was a two-year teacher professional master's degree program for 60 in-service classroom teachers at a large, mid-Atlantic public university with a large and diverse undergraduate population, but a predominately White graduate school of education. The P-12 teachers enter the cross-disciplinary program as part of a school-based team and the curricular emphasis over the two-year cohort is to explicitly address issues of social justice in educational policy, critical pedagogy in classroom curriculum and teacher practice, collaboration, teacher reflective practice, and teacher leadership outside the P-12 classroom. The faculty intends for the teachers to develop as critical educators in their own classroom settings. The entire cohort is team-taught by as many as four faculty members.

This study involved two levels of investigation. As earlier stated, in Phase I, there were two faculty researchers (who are also poets) who interviewed respondents about their experience with schooling and then wrote poetry based on the data that was later videoed. The last part of Phase I included showing the video to their graduate students who were in-service classroom teachers who were asked to write about their responses to the video. In Phase II, two other faculty researchers in the same graduate program introduced the video and a poetic form to a different set of graduate students who were in-service classroom teachers. This article is primarily about Phase II and describes Phase I as context.

Qualitative methods were used in all stages of the research. Phase I used methods including autoethnography (Leggo, 2008), oral history (Grele, 2007), and hybrid ABER research (Cahnmann-Taylor, 2008). Phase II used media analysis, experiential learning, interviews, and teacher self-reflection essays.

\section{Phase 1 Methods}

In the first phase of the research, the two poet-teacher educatorsresearchers (View and Hanley) asked a broad spectrum of students, colleagues, and acquaintances:

Tell me your memories and stories about your experiences in schools, first as a child, then as an adult, then as a parent (if applicable). What were/are the best of times? What were/are the worst? Describe the place and people. 
The questions were not about race; nevertheless, while none of the White interviewees spoke about race, all of the people of color mentioned race as a significant element of their schooling experience. Finding this to be provocative, the researchers used convenient sampling to conduct, record, and transcribe oral history interviews (ranging from 90 minutes to four hours) with one American Indian woman, two Latino/as, and two African Americans. The choice of collecting oral histories, which Grele (2007) defines as "a conversational narrative created by the interaction of the interviewer and the interviewee," provided the first level of storytelling, a relationship in which the interviewer and interviewee reconstructed history together ( $p$. 12). Grele posits that the interviewer shapes the story by providing a contemporary context of scholarship and study, and the interviewee reconstructs lived experience in relationship to the interviewer's queries. A complex network of meaning, identities, and purposes forms a reconceptualization of the past that is negotiated in the oral history conversation. Figure 1 provides a description of the people interviewed.

\begin{tabular}{lllll} 
NAME* & GENDER & AGE & ETHNICITY & OCCUPATION \\
Keisha & Female & 13 & African American & Middle school student \\
\hline Lela & Female & 30 & Latina & $\begin{array}{l}\text { Doctoral student in education, } \\
\text { Community activist }\end{array}$ \\
\hline
\end{tabular}

\begin{tabular}{lllll}
\hline Melvin & Male & 38 & African American & Principal of middle school \\
\hline Miguel & Male & 60 & Chicano & Social worker \\
\hline Laurel & Female & 30 & Native American & Publications specialist \\
\hline
\end{tabular}

Fig. 1: Phase I interview subjects ( ${ }^{*}$ All names are pseudonyms)

Using a descriptive and interpretive analysis of the data (Miles \& Huberman, 1994) we highlighted, made notes, and coded each interview transcript.

In addition, one researcher produced an autoethnography of her son's educational experiences (e.g., Leggo, 2008). To do the auto-ethnographical work, the researcher/poet used memories, journals, notes, photographs, and poems she wrote to reexamine experience through the lens of an African American educator who lives as an outsider and insider in academia. The data were analyzed by reading and examining the artifacts several times alone and with others and writing memos that included memories of experiences and present-day feelings and perceptions. 
Salient themes emerging from both analyses included race, racism, supremacy, class, gender, marginalization, resistance, learning, segregation, achievement, failure, family, teachers, fear, anger, pride, and community and were repeated across the transcripts. From these themes, we constructed poems on the individual experiences and developed findings on the collective experience of race in education. Some of the language in the poetry comes verbatim from the data and the poems were read by most of the respondents to validate the meaning represented. This phase of the project is a demonstration of the form of ABER that Cahnmann-Taylor (2008) describes as hybrid research which she states "combines tools used by the literary, visual, and/or performing arts with tools used by educators and other social scientists to explore the human condition" (p. 9). The following poem, Fencewalker, by View is an example of the poetry. To offer context, the interview subject Laurel Blackstone is a 30-year-old Native American woman who grew up in a large city in the Southwest near the reservation where her mother was born.

\section{Fencewalker}

Maybe in the Pima or Creek traditional languages

My name would be

Fencewalker,

Feet-Impaled-By-Expectations

Or

Maybe my punk name would be

Trans-Viva:

Messenger-For-This-Other-Life

I did not ask for the honor

Or honors,

Or smart-people classes

Did not ask to

feel ashamed

be assumed Latina

not recognize my own rez cousins in the tracked hallways of our school

If asked,

I would choose, instead,

To flee,

Naked 
With half-Black, half-Indonesian Tony

And my same Gila River cousins saddled with GEDs and multiple kids

And my mom

And anyone else invested

In friction

To shoot sparks -

No, rockets!! -

in the dark sky

We'd mediate our zany, rebellious designs and

Grow a responsible round community

Of dark, smart people

Snatch back our stories from wealthy white curators

Share them among ourselves

And anyone who honored us

And our courses

Our voices

Our new traditions

Advanced placement

In a vibrant meadow of justice

View and Hanley read the poems for various audiences of colleagues, students, and community members. Subsequently, they created a video of a reading of the poetry to be shared with a variety of audiences (http://www.myspace.com/video/ stoney1/lemniscating-counter-narrative/49123329).

At one of the professional conferences where the video was shown by the poet-researchers, two colleagues participated in a poetry meaning-making exercise, which they subsequently transformed for use with their cohort of graduate students, creating Phase II of the inquiry.

\section{Phase II Methods}

Here, a second pair of researchers (Stribling and DeMulder) used the video as part of the culminating assignment for their Language and Culture course in 2009. In a semester-long "Knowing project: An epistemological exploration of community life and meaning-making," sixty P-12 in-service teachers explored the language and culture of someone whose view of the world and of themselves was vastly different 
from their own. They were challenged to move beyond stereotypes to complicate their understanding about an unfamiliar culture with the help of a person who identified him/herself with that culture.

Once they identified a person who would "host" their exploration of culture, teachers critically examined how this person's "culture" was represented in the media, reflected on their own assumptions about this person and his/her culture, engaged in at least two exchanges with their "host" and his/her culture, and reflected on what they learned about their host's culture and about themselves through the exchanges and what the experiences might mean for them as teachers. Teachers brought their narrative reflections to class where they had the opportunity to deepen their experience through the use of poetry.

Teachers first viewed the aforementioned video of the poetry performance. Then they were tasked with using the data they collected during their Knowing Project to present their counter-narrative through poetry to introduce their host to their teacher peers. They could construct the poem from scratch or by using a form provided. A list of literary techniques was also provided for them to consider (e.g., simile, metaphor, alliteration, etc.).

After composing their poems, teachers shared them in three small groups of about 20 teachers each. They prepared up to three sentences to explain their reasons for choosing this person and then read their poem in a Reader's Theatre style. A discussion followed where the teachers shared how the poetry enhanced their understanding of their own and other cultures.

One example follows of a teacher's poem and statements:

You are caring and dedicated

You wonder how to overcome prejudice

You hear angels from Heaven

You want to help everyone

You are caring and dedicated

1. She was from a culture l'd seen in movies and was curious about (Greek)

2. She was a positive person who felt underrespected due to her culture

3. I respected her for her dedication to teaching and her caring for her friends and family 
All 60 teachers created poems of varying quality. The written reflections about this process, collected electronically from the teachers after the class day, were most revealing of the transformative process. We read through these reflections to look for recurrent themes (Creswell, 1998; Marshall \& Rossman, 2006) related to their experiences with this creative endeavor.

\section{Results}

The following themes and subthemes emerged from the data analysis process:

\section{Insights About the Process of Writing a Poem}

Most of the teachers described insights they gained about the process of writing a poem as a result of engaging in the activity themselves. The following subthemes were evident:

Writing poems (and the power of words) provided a different and/or additional opportunity to reflect on the person and the experience, allowing for deeper reflection and understanding. Teachers wrote: "There is something about poetry that seems to make words become more powerful"; "It was interesting to share my poetry because I was able to really give a sense of what I learned"; "Wow, at the end of the day, this was exponentially more powerful than I ever imagined."

Writing poems required a careful/thoughtful choice of words to get to the essence of the person. For example, teachers wrote: we had to "put our writing on a diet"; "we were able to summarize our most intense, influential, and important things we learned about the person we interviewed."

Writing poems revealed talents and multiple ways to express ourselves. For example, a teacher reflected that these kinds of activities "bring out talents that all of us have but don't know we have."

Writing poems involved an emotional response. For example, teachers responded: "I learned that my subject's story still breaks my heart as I was not able to read the poem aloud without tearing up"; “...the emotional underpinnings of the arts helps further cognition"; "This specific activity deeply reached into my affective domains. I'd like to do more of these in the future. I felt so much closer to the people 
of different cultures and backgrounds through listening to the poems, as my fellow teacher friends wrote them with their hearts."

Writing poems helped to foster greater empathy. Teachers responded: “... to write a poem it really forced me to take on that person's identity to think about their wants and needs"; "It made me look at their perspective-I think during this project I was looking at it through my perspective-I thought I was very interesting..."

Writing poems encouraged creativity. Teachers wrote: "I learned that I had some creativity in my brain"; "I loved the opportunity to create this way. It allowed for my creativity to come through and to hear intimate thoughts from others as well"; "Not only was I surprised at my own abilities of creating a poem, I was impressed with others' poems and the creativity and care they took to describe their project and the significance of their knowing project."

Writing poems reinforced the importance of stories. Teachers reflected: "I learned that everyone has a story. Every person you pass on the street, the person driving too slow in front of you, the mom frustrated with her kid at the mall-we all have stories, and judgment really means nothing until you have taken the time to truly listen and understand someone else"; "I was impressed with the beauty of the way the stories were told. It makes you realize that every child has a story. Using poetry to tell these stories makes them into an art form and helps bring meaning to what they want to convey in a simple, concise but very powerful way."

\section{Writing a poem was a challenging experience and the scaffolding process} (providing a format) for writing the poems made it less formidable a challenge. Teachers wrote: "I enjoyed forcing myself to try to write a poem that truly reflected the person I had learned more about"; "The creative aspect of developing the poetry for the Knowing Project was lost upon me. While I understand the aspect of taking an in-depth project and reducing it to a few important words, I typically write in a condensed manner that often leaves out the additional fluff. Attempting to write it in poetry form then sharing my (horribly-written) poetry was a very stress-inducing experience for me"; "I was really worried all day about writing poetry until we were given the outline. That really helped. Then it was hard to put all the things I wanted to say into a few statements. But having to do this helped bring out the important things you wanted others to know. It was a good way for everyone to contemplate their experiences with their knowing projects participants and be able to briefly share the most meaningful parts with the whole group"; "It was helpful that you gave us an outline to use when creating our poem. Since I am not much of a creative writer, this 
helped guide me in the right direction and made the activity seem less overwhelming to me. This is something that I feel I need to keep in mind with my students."

\section{Insights from Sharing Poems Aloud}

Several teachers specifically commented on the experience of sharing the poems aloud as a group [in a reader's theatre format]. For example, teachers wrote: "Listening to everyone read theirs, without interruptions or discussion was amazing"; "I learned that I felt very vulnerable when reading my poetry aloud. It was like my true thoughts were put out for everyone to hear and criticize."“I enjoyed the poems....they were very powerful! I think you should have everyone type theirs up and submit it, write an introduction, publish them. As I sat there listening to everyone's poems, they were very similar. I think we all experienced a new level of acceptance."

\section{Implications for and Insights About PK-12 Classrooms and Student Learning}

Many teachers expressed interest and enthusiasm in using a poetry format/ activity in their own classrooms. More importantly, teachers responded with insights about the profound impact this or similar experiences can have on learning and significant insights about their own practice as a result of the experience. For example teachers said, "It was an interesting experience but I've always been open to multiple ways of sharing learning, even if I don't do as good a job allowing it in my classroom as I'd like"; "I'm interested to share the poem with my person, and see if they feel as though it encapsulates them in some way. It's quite possible that my view of him is different from his own view. This is another lesson learned from the Knowing Project and it has direct implications in the classroom. Even when I think I know a student, I need to keep in mind that it is from my perspective, and allowing them to present their thoughts and ideas from their perspective is a critical piece to the conversation"; "I didn't expect to feel vulnerable when sharing my poem. I did. It was very personal and close to my heart. I wonder if and when my students may feel this vulnerability? And I am totally unaware of it..."; "What I did take away, though, was the profound impact that that kind of medium can have on the learner. Poetry in particular is often an intensely personal way of dealing with material, and you can't help but become engaged as a result. I do question its effectiveness in a forum setting simply because of its personal nature though. The beauty of poetry is that it speaks differently to each listener, but at the same time is embodying the voice of its creator...which may have had a completely different intent. As a means of instruction, then, I have issues with its utility. As a means of getting students to grapple with issues/content within the 
confines of their minds, however, I think that it's an invaluable tool that is probably underutilized in the classroom."

\title{
Concern About the Practice of Discouraging Creativity in Schools
}

One teacher reflected: "I think it is very sad that the rule is that children are enthusiastic about learning up until they start going to school where their creativity and natural curiosity are smashed to smithereens because of the curriculum and the fear of many of us teachers to think outside the box and create that multicultural and pedagogic revolution Nieto and Freire describe in their books. I wonder if many of us are afraid of taking those steps for the very reason our students lose their enthusiasm. Could it be that we do not have enough faith in ourselves and the power we have to change the world around us? Could it be too late? Could it be that nobody cares about us or they stopped caring so we stopped believing?"

These data suggest that the Phase II research took the intentions of Phase I to more profound levels of insight, producing a continuously looping interplay of arts-based educational research and dialogue, which produced counter-narrative, which provoked cognitive dissonance (e.g., Festinger, 1957; Gorski, 2009) leading to a resolution that disabused the creators and percipients of stereotypes, driven by a process of creativity.

\section{Discussion}

The following themes and subthemes emerged from the analysis process of Phases I and II:

\begin{abstract}
ABER
The Phase I researchers referred explicitly to Prendergast's (2007) notion that "Poetic inquiry is sometimes a socio-political and critical act of resistance to dominant forms and an effective way to talk back to power" (p. 1) They were interested in expressing the socio-political concerns of their oral history interviewees, as an act of witness, and as a way to express the affective experiences of people who are often ignored or unheard in educational settings. Their creative process also served the goals of critical race theory by generating counter-narratives. Similarly, the P-12 teacher researchers in Phase II used the data gathered over the course of a semester
\end{abstract}


to enter into a creative process to understand the data gleaned from their host in the Knowing Project and their own experiences of another culture.

\section{Dialogue}

The creative processes in both phases of the research involved dialogue at many levels: intrapersonal (through reflection and mini-c creativity); dialogue with the materials of poetry-making (words, verbatim quotations, and poetic concepts such as rhyme, alliteration, metaphor); dialogue with the data sources (be they interviewees, Knowing Project hosts, the sights and smells of the Knowing Project communities, etc.); dialogue with percipients; and interpretation, a type of dialogue in which a "story" is told, retold, observed, and told again moving the art-maker from the lower to higher levels of Bloom's Taxonomy.

\section{Counter-narrative by Way of Cognitive Dissonance}

In addition to the art makers in Phase I offering percipients a counter-narrative to the stereotypes and master narratives that are told about people and communities perceived as "different," the data suggest that Phase II art makers arrived at counter-narratives through their engagement with the creative process. As the art makers encountered information that failed to conform to their previously held views, they struggled to understand the meaning of the information and the extent to which it would threaten or transform their reality. In their efforts to restore cognitive balance (Festinger, 1957), all of the art makers eventually shifted their reality to accommodate the new information received from their data sources and created a new story as a result. They made connections with people and places they had never made before, as well as making connections with how the insights could inform and transform their own learning, their classroom, and their teaching practice. The data suggest that to act and think differently about various oppressions means moving beyond cognitive dissonance through a creative process.

\section{The Process of Creating}

The art-making process provided Phase II graduate students a way to "know" difference, to step outside of their own skin to gain perspective of another person toward achieving empathy. Their creativity, as manifested in reflections on the poemmaking process and the sparks evoked in terms of their own classroom instruction, eventually brought them joy. However, creativity required effort. The task of creating poetry was daunting for many students even though they were supported through 
the process. They were surprised at the level of learning and depth of the insight they developed through the process, despite the way that the creative process provoked discomfort and vulnerability.

Coming full circle, the data suggest that the personal risk-taking that is required in a creative process evokes subjectivity and vulnerability, produces cognitive dissonance and resistance, and eventually moves the art-maker through discomfort to a satisfying learning as manifested by a work of art. Even the students who expressed the greatest resistance to art-making or identifying themselves as artists, eventually found value in the process:

The poem was a challenge for me; one that I had never really been asked to do before, but I enjoyed forcing myself to try to write a poem that truly reflected the person I had learned more about.

I really didn't connect to this part of the day. I'm not an artist, so it was great to hear the stories but it was not something I could turn around and use. It was a good way to synthesize the project. I am not a poet so the stems were such a great idea.

I was dreading this part of the day. Poetry. We had to write a poem? Once I actually got into the activity, I found it incredibly meaningful. I loved hearing everyone's poem and getting to know their person through the poem.

Much like theories that argue that deep learning can only come through risk taking, stress, disequilibrium, and accommodation (e.g., Csíkszentmihályi, 1997; Piaget, 1985), the P-12 classroom teachers, in spite of reluctance and fear, survived an arts-based educational research process, gained insights about themselves and others, and seemed to be the better for it.

\section{Conclusion}

The poem-making process had the impact of de-centering the participants. This somewhat unsettling experience led to important insights regarding the person they came to "know" as part of the Knowing Project and led to significant insights regarding the teachers' own practice and the dearth of opportunities for creative and artistic expression in schools. 
Our greatest hope is that teachers' engagement with creative and artistic processes will encourage them to then use these processes with their own students; if teachers can learn so much through these alternative mediums, then certainly their own students could as well. In fact, many researchers have found strong connections between the arts and learning. For example, sociodramatic play as a way to meaningfully engage young children with literacy tasks and skills helps facilitate their construction of literacy knowledge and understanding (e.g., Christie, 1998; Hall, 2000; Levy, Wolfgang, \& Koorland, 1992; Roskos \& Christie, 2001). Through interactions with materials, print, and others, children begin to understand the communicative power of reading and writing and learn how to comprehend and manipulate language. Vivian Gussin Paley's (2004) work is compelling evidence for the power of "play." She has the children dictate stories that they then dramatize with and for their peers; as she claims, "play [is] indeed work" (p. 2). Furthermore, Connery, John-Steiner, and Marjanovic-Shane (2010) argue that, "...the very nature of learning is creative" (p. 215). Infusing the arts into the curriculum at all levels-from Preschool through Higher Education-is essential for deep and meaningful learning to occur.

There is typically no expectation of creativity in the context of teacher professional development programs. This is particularly the case in a national education policy environment that defines and rewards teaching and learning in terms of high stakes test scores rather than in terms of creativity and play. Yet, the revised Bloom's Taxonomy, the Common Core Curriculum (National Governors' Association, 2010), Understanding by Design (Wiggins \& McTighe, 2005), and other constructs demand that teachers exhibit considerable creativity in their curriculum design and instruction. The challenge then for teacher educators is to support each learner in their individual growth, to move toward greater cognitive complexity. When principles of constructive-developmental theories inform and shape the design of teacher professional development experiences, teachers engage in transformative meaning-making by critically reflecting on the world and on their practice, constructing professional knowledge with their peers, and developing more collaborative relationships with their fellow teachers (Gregson \& Sturko, 2007). Equally important is the evidence that the arts are necessary for children's intellectual development (e.g., Connery, John-Steiner, \& Marjonovic-Shane, 2010) and classroom teachers are important conveyors of this message. 


\section{References}

Barone, T. (2008). How arts-based research can change minds. In Arts-based research in education (pp. 28-49), edited by M. Cahnmann-Taylor and R. Siegesmund, 28-49. New York: Routledge.

Barone, T., \& Eisner, E. (1997). Arts-based educational research. In Complimentary methods for research in education (pp. 73-79), edited by R. M. Jaeger, 73-79. Washington D.C.: AERA.

Beghetto, R. A., \& Kaufman, J. C. (2007). Toward a broader conception of creativity: A case for "mini-c" creativity. Psychology of Aesthetics, Creativity, and the Arts, 1, 73-79.

Brooks, G. (1967). The Chicago Picasso. CUNY Composers. Ed. Corbett Treece. <cunycomposers.wetpaint.com>. Retrieved from http://cunycomposers.wetpaint.com/pag e/\%22The+Chicago+Picasso $\% 22 \% 3 \mathrm{~A}+\mathrm{Pa}$ blo+Picasso+and+Gwendolyn+Brooks

Bümen, N. T. (2007). Effects of the original versus revised Bloom's taxonomy on lesson planning skills: A Turkish study among pre-service teachers. International Review of Education, 53(4), 439-455.

Cahnmann, M. (2003). The craft, practice, and possibility of poetry in educational research. Educational Researcher, 32(3), 29-36.

Cahnmann-Taylor, M. (2008). Arts-based research: Histories and new directions. In Arts-based research in education (pp. 3-15), edited by M. Cahnmann-Taylor \& R. Siegesmund,. New York: Routledge.

Christie, J.F. (1998). Play as a medium for literacy development. In D.P. Fromberg \& D. Bergen (Eds.), Play from birth to twelve and beyond (pp. 50-55). New York: Garland Publishing.

Connery, M.C., John-Steiner, V.P., \& MarjanovicShane, A. (2010). Vygotsky and creativity: A cultural-historical approach to play, meaning making, and the arts. New York: Peter Lang.

Creswell, J.W. (1998). Qualitative inquiry in research design: Choosing among five traditions. Thousand Oaks: Sage Publications.
Csíkszentmihályi, M. (1997). Finding flow: The psychology of engagement with everyday life. New York: Basic Books.

Decuir, J.T., \& Dixson, A.D. (2004). "So when it comes out, they aren't that surprised that it is there: Using critical race theory as a tool of analysis of race and racism in education. Educational Researcher, 33(5), 26-31.

Delgado, R., \& Stefancic, J. (2001). Critical race theory: An introduction. New York: New York University Press.

Doyle, C. L. (2011). Dimensions of the creative episode: Old categories, new perspectives. Creativity Research Journal, 23(1), 51-59.

Egan, K. (1992). Imagination in teaching and learning: The middle school years. Chicago: University of Chicago Press.

Eisner, E. (1980.) Artistic thinking, human intelligence, and the mission of the school. The High School Journal, 63(8), 326-334.

Eisner, E. (1995). Is arts based research an oxymoron? Presented at the Annual Meeting of the American Educational Research Association, San Francisco, California.

Eisner, E. (2008). Persistent tensions in artsbased research. In Arts-based research in Education (pp. 16-27), edited by M. Cahnmann-Taylor \& R. Siegesmund. New York: Routledge.

Festinger, L. (1957). A theory of cognitive dissonance. Stanford, CA: Stanford University Press.

Geertz, C. (1973). The interpretation of cultures. New York: Basic Books.

Gorski, P. (2009). Cognitive dissonance: A critical tool of social justice teaching. Retrieved from http://www.edchange.org/publica tions/cognitive-dissonance.pdf

Gregson, J.A., \& Sturko, P.A. (2006). Teachers as adult learners: Re-conceptualizing professional development. Journal of Adult Education, 36(1), 1-18.

Grele, R. J. (2007). Reflections on the practice of oral history: Retrieving what we can from an earlier critique. Suomen Antropologi: 
Journal of the Finnish Anthropological Society, 32(4), 11-23.

Hall, N. (2000). Literacy, play, and authentic experience. In K.A. Roskos \& J.F. Christie (Eds.), Play and literacy in early childhood: Research from multiple perspective (pp. 189-204). Mahway, NJ: Lawrence Erlbaum Associates.

Hanley, M.S., \& View, J. L. (2010). Lemniscating counter-narrative: Oral history, autoethnography, and arts-based educational research in search of race in education. Paper presented at the meeting of The American Educational Research Association, Denver, CO.

Kegan, R. (1982). The evolving self: Problem and process in human development. Harvard University Press.

Krathwohl, D. (2002). A revision of Bloom's taxonomy: An overview. Theory Into Practice, 41(4), 212-218.

Ladson-Billings, G., \& Tate, W. F. (1995). Toward a critical race theory of education. Teacher's College Record, 97(1), 47-68.

Leggo, C. (2008). The ecology of personal and professional experience: A poet's view. In Arts-based research in education (pp. 89-97), edited by M. CahnmannTaylor and R. Siegesmund,. New York: Routledge.

Levy, A.K., Wolfgang, C.H., \& Koorland, M.A. (1992). Sociodramatic play as a method for enhancing the language performance of kindergarten age students. Early Childhood Research Quarterly, 7, 245-262.

Lynn, M. et al. (2002). Critical race theory and education: Qualitative research in the new millennium. Qualitative Inquiry, 8(1), 3-6.

Marshall, C., \& Rossman, G.B. (2006). Designing qualitative research (4th ed.). Thousand Oaks: Sage Publications.

Mezirow, J. (1990). How critical reflection triggers learning. In J. Mezirow (ed.) Fostering critical reflection in adulthood (pp. 1-20). San Francisco: Jossey-Bass.

Mezirow, J. (1991). Transformative dimensions of adult learning. San Francisco: Jossey-Bass.

Miles, M., \& Huberman, A.M. (1994). Qualitative data analysis. Thousand Oaks: Sage.
National Governors Association Center for Best Practices, Council of Chief State School Officers. (2010). Common Core State Standards Washington DC: National Governors Association Center for Best Practices, Council of Chief State School Officers.

Paley, V.G. (2004). A child's work: The importance of fantasy play. Chicago: The University of Chicago Press.

Piaget, J. (1985). The equilibration of cognitive structures: The central problem of intellectual development. Chicago: University of Chicago Press.

Prendergast, M. (2007). "Poetic Inquiry is ... 29 Ways of Looking at Poetry as Qualitative Research," Educational Insights. Retrieved from http://www.ccfi.educ.ubc.ca/publi cation/insights/call/poeticinquiry.html

Renshaw, P. (2004). Dialogic learning teaching and instruction: Theoretical roots and analytical frameworks, in J. Van Den Linden \& P. Renshaw (Eds.) Dialogic learning: shifting perspectives to learning, instruction and teaching (pp. 1-15). London: SpringerLink

Revised Bloom's Taxonomy. (n.d.). Retrieved from http://www.bing.com/images/searc $\mathrm{h}$ ?q=blooms+taxonomy+chart\&view=de tail\&id=9BF9E4CE42E3FDB175F5CB6B2B0 F78D1C4CE621E\&first $=0$

Roskos, K., \& Christie, J. (2001). Examining the play-literacy interface: A critical review and future directions. Journal of Early Childhood Literacy, 1(1), 59-89.

Runco, M. A. (1996). Creativity and development: Recommendations. New Directions for Child Development, 72(Summer), 87-90.

Shor, I. (1992). Empowering education. Chicago: University of Chicago Press.

Wiggins, G., \& McTighe, J. (2005). Understanding by Design, Expanded 2nd Edition. Alexandria, VA: ASCD

Wink, J. (2005). Critical pedagogy: Notes from the real world (3rd ed.). New York: Addison Wesley Longman. 


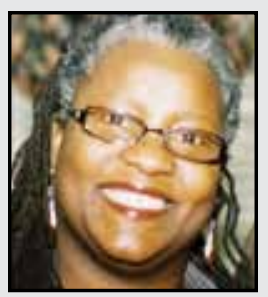

Jenice L. View is an Assistant Professor at George Mason University with a research focus on critical teacher professional development, critical history education, and the uses of arts integration. Dr. View is a co-editor of the widely used book Putting the Movement Back Into Civil Rights Teaching (2004) and of Why Public Schools? Voices From the United States and Canada (forthcoming). She is also the creator, producer, and host of the award-winning television public affairs program, Urban Education: Issues and Solutions

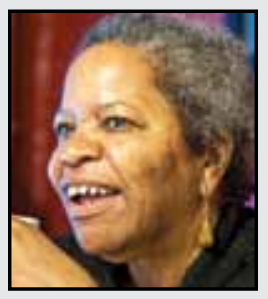

Mary Stone Hanley has been an educator in public and higher education for more than 40 years. She earned a B.A in Children's Theater, an M.Ed. in Educational Communications and Technology, and a PhD in Curriculum and Instruction, multicultural education, and drama from the University of Washington, Seattle. Since 1996, she has taught arts education and multicultural education courses in higher education and researched topics such as drama for K-12 students, hip hop culture, and the arts for adult learners. She is founder and president of Hanley Arts \& Associates, a professional and curriculum development consultancy in arts and equity education.

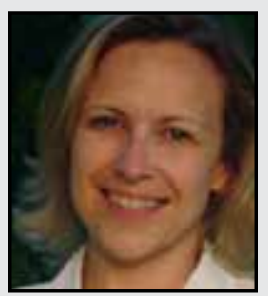

Stacia Stribling is an Assistant Professor in the Initiatives in Educational Transformation (IET) Master's Program at George Mason University. Prior to academia, Stacia worked for eight years as a first- and second-grade teacher in Fauquier County, VA. Her research interests include early childhood education, literacy, teacher professional development, and culturally responsive teaching practices. Stacia is also an advocate for arts integration in PK-12 classrooms. She holds a degree in flute performance and currently plays with the Piedmont Symphony Orchestra, the Woodbridge Flute Choir, and several local theater companies. 


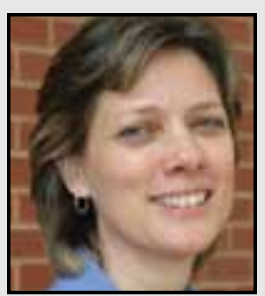

Elizabeth DeMulder is an Associate Professor in the College of Education and Human Development at George Mason University. Although a broken ankle halted her early training to become a professional ballet dancer, she has always been interested in incorporating the arts and supporting creativity in PK-12 classrooms and teacher professional development contexts. Her research concerns the study of interpersonal relationships and impacts on learning and development, including risk and protective conditions in children's education and development. Her recent focus has been on teacher professional development and the teaching and learning processes involved in critical pedagogy and multicultural education approaches.

LINKTO:

http://www.myspace.com/video/stoney1/lemniscating-counter-narrative/49123329 